$\begin{array}{ll} & \text { Etnográfica } \\ \text { etnográfica } & \text { Revista do Centro em Rede de Investigação em }\end{array}$

Antropologia

vol. 17 (2) | 2013

Vol. $17(2)$

\title{
Charles Westin, José Bastos, Janine Dahinden e Pedro Góis (orgs.), Identity Processes and Dynamics in Multi-Ethnic Europe
}

Joana Azevedo

\section{(2) OpenEdition}

\section{Journals}

\section{Edição electrónica}

URL: https://journals.openedition.org/etnografica/3173

DOI: 10.4000/etnografica.3173

ISSN: 2182-2891

\section{Editora}

Centro em Rede de Investigação em Antropologia

Edição impressa

Data de publição: 1 junho 2013

Paginação: 427-430

ISSN: 0873-6561

\section{Refêrencia eletrónica}

Joana Azevedo, «Charles Westin, José Bastos, Janine Dahinden e Pedro Góis (orgs.), Identity

Processes and Dynamics in Multi-Ethnic Europe», Etnográfica [Online], vol. 17 (2) | 2013, posto online no dia 20 junho 2013, consultado o 11 fevereiro 2022. URL: http://journals.openedition.org/etnografica/ 3173 ; DOI: https://doi.org/10.4000/etnografica.3173

\section{(c) (7) (8)}

Etnográfica is licensed under a Creative Commons Attribution-NonCommercial 4.0 International License. 
nismo português" (p. 93). Recorrendo a um manancial de discursos - destilados de documentos programáticos, comunicados oficiais e conferências de imprensa, de relatórios de ação relativos às várias campanhas (p. 226), ou das "múltiplas vozes" captadas a nível local, que abarcam a imprensa regional e os boletins paroquiais -, a autora consegue delinear um campo de posições que são, apesar das várias contradições, inteligíveis. Alguns relatos em primeira mão contrariam certas ideias feitas (p. 362), mostrando a pertinência dos métodos usados.

Quanto aos aspetos menos satisfatórios desta obra, salientem-se apenas dois: (1) as notas de rodapé, longas e abundantes, que interrompem a leitura com demasiada frequência, e cuja informação, pertinente na maior parte dos casos, poderia ter sido integrada no corpo do texto ou, em casos extremos, remetida para um anexo (ex. nota 118 , pp. 142-143, com os estatutos dos conselhos de aldeia, ou a citação incluída na nota 122 , p. 145, que ocupa a quase totalidade da página); (2) a fraca presença de registos visuais - sobretudo tendo em conta o con-

Charles Westin, José Bastos, Janine Dahinden e Pedro Góis (orgs.) IDENTITY PROCESSES

\section{AND DYNAMICS IN MULTI-ETHNIC EUROPE}

IMISCOE Research series, Amesterdão, Amsterdam University Press, 2010 , 375 páginas, ISBN: 978-90-8964-046-8.

Pensar a(s) diversidade(s) na Europa contemporânea é o objetivo genérico desta coletânea. De que modo se podem estu- tacto da autora com vários acervos desta natureza, a que o texto faz alusão.

De resto, este é um trabalho que merece ser amplamente lido e discutido. Não cedendo a relativismos paralisantes, nem à aporia da complexidade, a autora consegue brindar-nos com um retrato cuidadoso das campanhas do MFA, revelando as suas principais tensões internas e externas, percorridas através de diferentes espaços e temporalidades, e perspetivadas por diferentes atores sociais. Tendo sido, no seu tempo, um dos principais palcos da disputa política, social e cultural, estas campanhas encontram ainda eco na cena política atual, manifestando-se quer na memória (no que a autora designa por "diálogo entre os dois tempos" - p. 385) quer nas lutas, de "classificação" e outras, que continuam a ter lugar nos nossos dias.

\section{Sofia Sampaio}

Centro em Rede de Investigação em Antropologia, ISCTE - Instituto Universitário de Lisboa, Portugal psrss@iscte.pt dar e comparar as relações interétnicas em países europeus com experiências históricas e atuais de diversidade tão distintas? De que modos a Europa tem vindo a governar as diversidades? O que se entende por identidade na atual Europa multiétnica? Como se constroem as identidades e as relações interétnicas? Como desenvolver novas estratégias metodológicas para estudar as identidades?

A coletânea reúne um amplo conjunto de estudos que partem de perspetivas disciplinares tão diversificadas como a da 
antropologia, sociologia, história, estudos migratórios ou estudos culturais, e que têm como desafio comum refletir sobre as relações interétnicas na Europa, e sobre as dinâmicas e os processos identitários em curso nas sociedades contemporâneas.

A ideia de organizar este volume nasce no seio dos encontros científicos organizados pela rede internacional de pesquisa IMISCOE, iniciados em 2005 por um núcleo que reuniu investigadores a desenvolver trabalho empírico no Reino Unido, em Portugal, na Holanda, na Suíça ou no País Basco. Os treze textos aqui coligidos resultam desse trabalho coletivo de debate sistemático das diferentes pesquisas individuais em relação a temas transversais, como as relações interétnicas, a identidade, as representações ou a discriminação. Essa metodologia de trabalho, que tem caracterizado o modo de trabalho da rede IMISCOE, traduz-se numa conseguida articulação entre os debates teóricos presentes nos diferentes capítulos e numa coerência de fundo da obra.

Um aspeto particularmente bem conseguido é a complementaridade e diversidade das estratégias metodológicas convocadas pelos autores: da análise de redes etnicossociais de albaneses na Suíça desenvolvida por Janine Dahinden, à investigação-ação que Flip Lindo conduziu durante um ano num autocarro frequentado por jovens no bairro de Pendrecht em Roterdão, ou ainda ao desenho pelo antropólogo José Bastos de uma complexa metodologia mista para analisar comparativamente as estratégias de auto-organização religiosa e familiar que determinam identidades e modos de inserção diferenciados em seis grupos étnicos em Portugal.

Sendo uma coletânea muito baseada em estudos empíricos, há uma atenção à discussão teórica sempre presente em cada texto, e em particular no primeiro e último capítulos. No capítulo introdutório, Charles
Westin desenvolve uma extensa contextualização histórica das concetualizações em torno da identidade e uma síntese dos atuais debates e tendências de pesquisa neste campo, ainda com uma incursão pelo modo como cada disciplina tem abordado teórica e metodologicamente estes debates. A encerrar a obra, José Bastos e Susana Bastos exploram o conceito de identidade a partir das perspetivas da antropologia, da psicologia, da sociologia e da filosofia.

A questão da construção das identidades é analisada de forma particularmente interessante por Marlene de Vries. A socióloga estuda os laços étnicos dos judeus na Holanda, grupo etnicorreligioso fortemente assimilado e secularizado, mostrando que os laços face ao judaísmo são bastante diversificados segundo a geração, o nível de educação ou a origem da família. A autora mostra como neste grupo está em curso uma transição para uma identificação étnica de tipo opcional e intermitente, onde uma dada herança étnica é permanentemente adaptada e seletivamente usada na significação do quotidiano. No final, o estudo coloca uma interrogação: como é que os judeus imaginam a sua continuidade como grupo agindo segundo formas tão fortemente individualizadas?

Aitor Ibarrola-Armendariz lança um desafio semelhante, mas neste caso a partir das representações da população basca acerca da imigração na região. $\mathrm{O}$ autor evidencia uma contradição que o velho provérbio espanhol "Del dicho al hecho hay un gran trecho" resume: um evidente desfasamento entre a autorrepresentação da população basca como sociedade idealmente aberta e culturalmente diversa e a sua efetiva atitude face aos imigrantes, em questões como a saúde, a educação ou o mercado de trabalho.

A coletânea reúne também um conjunto de estudos que são um inequívoco contributo para as pesquisas sobre o(s) 
transnacionalismo(s). Desde logo, o estudo de caso de Janine Dahinden sobre os migrantes albaneses oriundos da ex-Jugoslávia em dois momentos do seu processo migratório: por um lado, na Suíça, a autora observa em que medida o género, cruzado com outras categorias sociais como a etnicidade, o estatuto legal ou a educação, estrutura as redes sociais destes migrantes, mostrando como a estrutura dessas redes está relacionada com a sua posição específica na sociedade suíça; por outro, no Kosovo, estuda as redes sociais de migrantes retornados ao país em finais dos anos 1990, após uma experiência migratória na Suíça, Alemanha ou Holanda. Neste olhar transnacional, Dahinden analisa de que forma as migrações transformam as perceções sobre o género, mostrando que no caso das mulheres albanesas retornadas a experiência migratória tornou muito mais difícil o seu processo de reintegração.

Numa perspetiva comparativa entre Portugal e a Rússia, o capítulo de Mário Artur Machaqueiro reflete sobre os efeitos das experiências colonialistas e pós-colonialistas, explorando as noções de "fronteira" e o seu significado no espaço europeu: a experiência colonialista portuguesa estendeu as fronteiras da Europa a África e à América do Sul, e no sentido inverso estas regiões são mais tarde trazidas de volta à Europa. De modo similar, também a Rússia é aqui pensada como região de fronteira com a Ásia.

As dinâmicas de poder pós-coloniais e as diferentes reinterpretações do sistema colonial são o enfoque do texto de Susana Bastos. A antropóloga analisa a dimensão política das identidades individuais de portugueses muçulmanos comparativamente a britânicos muçulmanos de origem gujarate residentes em Leicester, no Reino Unido. Os debates identitários entre os dois grupos remetem, em grande medida, para as diferenças da sua experiência colonial e para uma identificação ambivalente com os respetivos colonizadores.
Um outro texto fundamental para discutir o transnacionalismo é o de Pedro Góis, sobre a forma específica de transnacionalismo que se desenvolveu na migração de Cabo Verde para a Europa e Estados Unidos, e os seus efeitos na expressão da identidade dos cabo-verdianos. O caso dos cabo-verdianos é também objeto de análise por parte de João Sardinha, que procura compreender o papel das associações de imigrantes na identidade e modos de integração dos cabo-verdianos na área metropolitana de Lisboa.

Situando-se igualmente no conjunto de estudos fundamentais para discutir migrações e transnacionalismos, salientaria o capítulo de Nuno Dias, sobretudo pela sua sólida análise das expressões contemporâneas dos racismos, da discriminação e da exclusão social em dois contextos comparados: Portugal e Reino Unido. Em análise, o caso dos hindus de famílias com origem em Gujarate, cujos percursos de mobilidade determinaram em gerações anteriores uma etapa migratória na África de Leste, e a emigração, após as independências africanas, para Portugal e para o Reino Unido. Grupos com diferentes trajetórias históricas são objeto de padrões de discriminação semelhantes nos dois países.

Consolidando a relevante expressão que os estudos portugueses assumem nesta coletânea internacional, é de destacar por fim o capítulo de Marta Vilar Rosales sobre as elites goesas católicas e o período colonial português em Moçambique. Com base em histórias de vida, a antropóloga reconstrói as trajetórias, posições e estratégias de integração adotadas por famílias goesas que vivem atualmente em Portugal.

Reunindo um conjunto fundamental de perspetivas críticas face às abordagens correntes, os estudos coligidos nesta coletânea alargam assim o debate sobre os processos identitários e as relações interétnicas, 
apontando caminhos às ciências sociais para ensaiar outros contextos, teorias, questões de pesquisa e metodologias que se afiguram como essenciais.

\section{Christian Hottin (org.)}

\section{LE PATRIMOINE CULTUREL IMMATÉRIEL: PREMIÈRES EXPÉRIENCES EN FRANCE}

Paris, Maison des Cultures du Monde e Babel, 201 1, 364 páginas, ISBN: 978-2-7427-8977-1.

Este livro de bolso insere-se na coleção Internationale de l'imaginaire (n.s., n. ${ }^{\circ}$ 25), dirigida por Chérif Khaznadar, e constitui o terceiro número dedicado ao património cultural imaterial (PCI). O primeiro número - Le patrimoine culturel immatériel: Les enjeux, les problématiques, les pratiques (2004) - constitui uma das primeiras reflexões sobre os contextos, limites e potencialidades da Convenção para a Salvaguarda do Património Cultural Imaterial da UNESCO (2003), e o segundo - Le patrimoine culturel immatériel à la lumière de l'Extrême-Orient" (2009) uma perspetiva sobre as experiências da China, da Coreia e do Japão em matéria de PCI, tidas como políticas-modelo que moldaram o espírito da Convenção de 2003. Por seu turno, este último livro versa sobre as primeiras experiências em França na implementação desta convenção. ${ }^{1}$ Tendo

I Aprovaram a Convenção de 2003148 países, comprovando o sucesso deste normativo (cf. $<$ http://www.unesco.org/eri/la/convention .asp $? \mathrm{KO}=17116 \&$ language $=\mathrm{E}>$, consultado a 30/4/2013).
Joana Azevedo

CIES-IUL, ISCTE - Instituto Universitário

de Lisboa, Portugal

joana.azevedo@iscte.pt

como ponto de partida a narrativa oficial da UNESCO (a França aprovou a convenção em 2006), o livro dá conta, em jeito de balanço, do trabalho desenvolvido sobre esta matéria no âmbito das políticas públicas dos últimos quatro anos.

As contribuições contidas no livro são de profissionais de várias instituições francesas ligadas ao património e de representantes da UNESCO que fazem, assim, parte da comunidade de especialistas que procura encontrar respostas aos desafios lançados pela Convenção de 2003, um normativo que aponta para um conceito mais líquido sobre património, uma perspetiva renovada e dinâmica sobre salvaguarda e um papel mais ativo das comunidades, seja na identificação e reconhecimento, seja na sua implicação no processo de proteção deste património. A tradução destas recomendações implica a revisão do papel das instituições e dos profissionais, um processo ainda recente para muitos países e que este livro procura clarificar, dando a conhecer os esforços realizados pela administração francesa no sentido de adequar as suas políticas e instrumentos às recomendações da Convenção de 2003.

Com efeito, esta convenção tem sido terreno fértil para a discussão sobre o conceito de património e tornou-se também objeto de estudo nos últimos anos, tal como é percetível pelo aparecimento de variadas publicações que atestam pelo menos duas abordagens: uma baseada na 